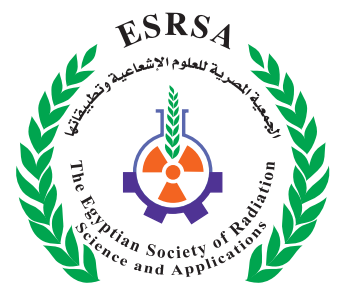

J. Nucl. Tech. Appl. Sci., Vol. 8, PP. 163 : 177 (2020)

\title{
Delayed Toxicity for Two Botanical Dusts on Black Cutworm, Agrotis ipsilon (Hufnagel)
}

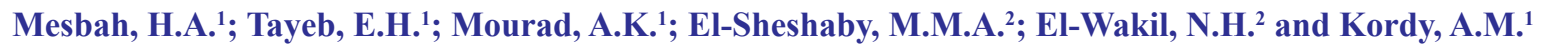

Received: 06/08/2020

Accepted: 18/10/2020

DOI: $10.21608 /$ jntas.2020.38217.1027

E.mail:akkm05@gmail.com

\section{ABSTRACT}

The latent delayed toxicity for two botanical Camphore and Jamson weed grass fine dusts on Agrotis ipsilon were studied. Whereas, all the evaluated rates of Camphor grass were highly efficient and the number of alive larvae ranged between 6 and 13 larvae out of 30 larvae compared to the untreated check (28 larvae). Furthermore, the delayed results clearly indicated the significant difference between the tested rates and their effect on the raised larvae and revealed its adverse biophysiological effects on the development of both (F1) and (F2) generation that followed by a complete failure of (F3) generation, compared to the untreated check.

The tested rates of Jimson weed grass fine dust caused significant reduction of the mean numbers in the surviving alive larvae of $A$. ipsilon and shows rapid complete failure to the development of the parent generation after larval treatment.

Finally, the obtained data showed the effectiveness of the mixture of each Jimson weed with Camphor at a rate of (3:1) and (3:3) gm. fine dusts on the developmental sequence of the larvae of the parent generation that were exposed to the prepared baits. Therefore, the aim of this study is to find alternative methods to reduce the effect of chemical pesticides on the environment.

1. Plant Protection Dep., Faculty of Agriculture, Saba-Basha, Alexandria University, Egypt-

2. Plant Protection Research Institute, Agriculture Research Center, Giza, Egypt. 


\section{INTRODUCTION}

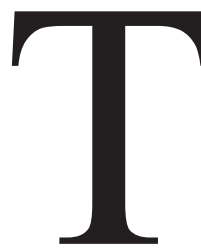

he black cutworm, Agrotis ipsilon (Hufn.) is considered to be one of the most notorious destructive phytophagous insect pest in Egypt, not only to cotton but also to many crops and vegetables (Salama $\boldsymbol{e t}$ al., 1970 and Kandil $\boldsymbol{e t}$ al., 2003). Because of the severe damage caused by the attack of this pest; it was found necessary to replace many crop plantations in many years (Abdel Hadi, 1980 and Elkifl et al., 1972).

Due to the high resistance and nocturnal feeding habits of the larvae, the black cutworm is considered to be very difficult to be controlled with insecticides (Han, 1986; Lie et al., 2002\&2008). The extensive use of insecticides, particularly those with long residual effect, resulted in several harm to the natural balance between pests and their enemies by killing many non-targeted organisms, long storage and sometimes very low degradation of the insecticides and in many cases high toxicity to mammals (Schmidt, 1986).

Reference to the several problems caused by insecticides and their residues, it amplified the need for effective and biodegradable pesticides with greater selectivity. Alternative strategies have included the investigation for new types of insecticides, and the re-evaluation and use of traditional pest control agents. One of the promising alternatives has been the use of medicinal plants due to containing a range of bioactive chemicals (Vanichpakorn et al., 2010) and are potentially suitable for use in integrated pest management (Schmuttere, 1992).

Therefore, in the recent years, several natural plant extract products have been considered potential alternatives to conventional insecticides as natural means of pest control (Mesbah, 1985; Mesbah et al., 1985, 1990, 1994 a\& b, 1995, 2004 and Rice and Coats, 1994).
Accordingly of the present study is to study the biological performance of the natural plant fine dust alone or mixture against the black cutworm and to investigate the delayed effect of these fine dusts on the fitness components of the consequently, raised generations post treatment of the parent ones.

\section{MATERIALS AND METHODS}

\section{A. Source of the black cutworm, Agrotis ipsilon (Hufn.)}

The used larvae of A. ipsilon (Hufn.) in the present study were obtained as newly deposited eggs from a laboratory culture, Department of Cutworm and Mole Crickets, Plant Protection Research Institute, Agriculture Research Center, Cairo, Egypt. The hatched larvae of the black cutworm were reared on castor oil leaves (Ricinus communis L.) under the higro-thermic conditions of $25 \pm 2{ }^{\circ} \mathrm{C}$ and $65 \pm 5 \%$ R.H., for many generations to obtain the sufficient number of insects needed for the experiment.

\section{B. Rearing technique}

According to the adopted rearing techniques by Beheedy (1990) and Abdel-Mageed (1997), the newly hatched larvae were kept in clean glass jar (1L.) and covered with muslin which was fixed tightly by a rubber band and provided daily with new castor oil leaves until the third larval instar. Then they were transferred to clean disinfected and larger glass jars (2L.) to limit or prevent the incidence of larval cannibalism. The bottom of each jar was covered with a thick layer of fine saw dust and the usual rearing technique was performed along the developing stages of $4^{\text {th }}, 5^{\text {th }}$ and $6^{\text {th }}$ larval instars till pupation occurred. The developed pupae were kept in a glass jars with paper towels on the bottoms and covered with gauze until adult emergence. The incipient adult-moths (males and females in ratio 1:1) were transferred to a bigger jar which was supplied with hanged piece of cotton moistened with $20 \%$ sugar solution in the space of the glass jar. Also strips of 
dark or/and white cloth fixed in the muslin cover for each jar were used as hanging sites for egg deposition by the mated female moths. Swaps of moistened cotton with the sugar solution were replaced every two days. Also, the muslin strips on which the eggs had been deposited were daily collected and transferred to new jars and left up to hatch. The neonates were fed on castor oil leaves and the colony of mass reared larvae was continued as above explained rearing technique. The needed $4^{\text {th }}$ instar larvae of the black cutworm for the initiated treatments were obtained from the colony.

\section{Materials and techniques used in the study}

\section{1- Natural plant fine dusts.}

The leaves of both selected plant species Camphor, Cinnamomum Camphora L. (Lauraceae) and Jimson weed grass, Datura stramonium L. (Solanaceae) were collected from different areas of ElBeheira and left to dry under room temperature; thereafter, introduced into an electric oven at $60^{\circ} \mathrm{C}$ till complete dryness. The dried leaves of each plant species were well crushed by means of an electric mill and sieved with a 100-mesh sieve to obtain their fine powder. The main chemical constituents of each evaluated fine dusts are exhibited on Table a (Claus et al., 1970).

\section{The treatment of the black cutworm with the tested natural plant fine dusts.}

The exhibited amounts on table $1 \mathrm{~b}$ elucidate the components and rates of carrier material and stimu- lants in preparing the baits of each of the evaluated plant fine dusts or/and their adopted mixtures in the tested baits during the study. For each evaluated plant fine dusts of Camphor and Jimson weed, five rates of $0.05,1,2,3$ and $4 \mathrm{gm}(\mathrm{w} / \mathrm{w})$ were added in the prepared bait. While the binary mixture of Jimson weed at rate of $3 \mathrm{gm}$ with Camphore ( $1 \& 3 \mathrm{gm})$. All of the tested mixtures were made before adding and mixing with the other used compounds of the bait. The exposure of the $4^{\text {th }}$ instar larvae to the fine dust bait was performed in plastic pans $(10 \mathrm{~cm}$, in diameter), on which the bait was scattered in regular small amounts. Treatments were run in three replicates, each contained 10 larvae. The exposure of the treated larvae on the bait extended along the lasted period from the beginning of the $4^{\text {th }}$ instar larvae exposure up to end of the $6^{\text {th }}$ instar larvae till the end of the experiment. In general, mortality counts and the investigated parameters of the fitness components were recorded post the larval treatment of the parent generation, and the following off generations according to the type of the tested plant fine dust, to determine the lasted time of the delayed effect till reaching the state of sterility. The evaluated malformed immature and/or adult moths were recorded, described at the same time.

\section{Statistical analysis}

All data were Statistically analyzed using Analysis of Variances (ANOVA)was run to compare the significance of differences between treatments .The least significant differences (L.S.D) were determined according to (Duncan, 1955).

Table (1a): The evaluated plant fine dusts and their chemical components.

\begin{tabular}{|c|c|c|}
\hline Common name & Scientific name & Chemical components \\
\hline Camphor & $\begin{array}{c}\text { Cinnamomum } \\
\text { Camphora }\end{array}$ & $\begin{array}{c}\alpha \text {-Pinene, camphene, } \beta \text {-pinene, sabinene, phellandrene, } \\
\text { limonene, 1, } 8 \text {-cineole, y-terpinene, p-cymene, terpinolene, } \\
\text { furfural, Camphor, linalool, bornyl acetae, terpinen-4- } \\
\text { ol, caryophyllene, borneol, piperitone, geraniol, safrole, } \\
\text { cinnamaldehyde, methyl cinnamate and eugenol }\end{array}$ \\
\hline Jimson weed & Datura stramonium & \begin{tabular}{c} 
tropane, atropine, hyoscyamine, and scopolamine \\
\hline
\end{tabular} \\
\hline
\end{tabular}


Table (1) : The comparative used amounts for preparing baits of the evaluated plant fine dusts in lab test.

\begin{tabular}{|c|c|c|c|c|}
\hline \multirow{2}{*}{$\begin{array}{c}\text { Site of } \\
\text { application }\end{array}$} & \multicolumn{2}{|c|}{ Bait components } & \multirow{2}{*}{ Plant fine } \\
\cline { 2 - 4 } & $\begin{array}{c}\text { Carrier material of } \\
\text { course corn flour }\end{array}$ & Water & Molasses & \\
\hline \multirow{2}{*}{ Lab } & $125 \mathrm{~g}$ & $100 \mathrm{ml}$ & $5 \mathrm{ml}$ & $\begin{array}{c}\text { Tested progressive rates. } \\
0.5,1,1.5,2,3 \text { and } 4 \mathrm{~g} .\end{array}$ \\
\hline
\end{tabular}

\section{RESULTS}

\section{Biological performance of Camphor fine dust on different developmental stages of A. ipsilon parent generation.}

The toxicity of the botanical fine dusts in the prepared baits against the $4^{\text {th }}$ instar larvae of the black cutworm A. ipsilon was determined under the laboratory hygro-thermic conditions of $25 \pm 2^{\circ} \mathrm{C}$ and $65 \pm$ 5\% R.H.

The presented data in Table (2) elucidate the influence of the tested rates $(\mathrm{g})$ of Camphor fine dust on the recorded mortalities and the development consequence of treated cutworm parent larvae post feeding on prepared baits. The number and the percent of the derived normal and malformed larvae, pupae and emerged moths, number of deposited eggs / female; hatchability and sterility percentages were calculated.

The data revealed the effect of feeding larvae on the prepared baits with different tested concentrations of Camphor leaves fine dusts $(0.5,1.0,2.0$, 3.0 and $4.0 \mathrm{~g}$ ) on the fitness component and exhibited malformation of A. ipsilon. All the evaluated conc. rates $(\mathrm{g})$ were highly efficient and the number of alive larvae ranged between 6 and 13 larvae out of 30 larvae, as compared to the untreated check ( 28 larvae).

Camphor fine dust at rate of $1.0 \mathrm{~g}$ gave the highest percent of larval mortality $(80.0 \%)$ followed by $76.67 \%$ at the tested rate of $3.0 \mathrm{~g}$. While the other tested rates of 2.0 and $4.0 \mathrm{~g}$. gave the same percentage of larval mortality that amounted to $(63.33 \%)$.
The lowest percent of $56.67 \%$ was detected at a rate of $0.5 \mathrm{~g}$, compared to $6.67 \%$ in the untreated check. The highest average number of the resulted pupae $(9.33 \pm 1.33)$ was detected in check treatment, versus the lowest observed average number of $0.67 \pm$ 0.33 in the treatment of $3.0 \mathrm{~g}$ Camphor fine dust. The highest pupal mortality ( $72.7 \%$ ) was recorded for the treatment of $4.0 \mathrm{~g}$, followed by both treatments of 3.0 and $2.0 \mathrm{~g}$ (71.4 and $54.5 \%$, respectively). The only malformed pupa was detected at the tested rate of $0.5 \mathrm{~g}$ (1.0 pupa).

Furthermore, the treatment of Camphor fine dust at $0.5 \mathrm{~g}$ reduced the percentage of the emerged adult $(88.8 \%)$, while all the other tested rates had no effect on the number of the emerged adults.

The number of the deposited eggs / untreated female was the highest (428 eggs) followed by the gradually decreased numbers up to $169.0 \& 85.0$ eggs in case of the used rates of $0.5 \& 2.0 \mathrm{~g}$. The highest percentage of recorded hatchability $(95.5 \%)$ in the untreated check to a more or a less extent decreased up to 75.0 and $60.0 \%$ in the case of the used rates of 0.5 and $2.0 \mathrm{~g}$ Camphor fine dusts, respectively.

The delayed effect of the Camphor fine dust treatment on the following survived generations of the black cutworm, Agrotis ipsilon post parent treatment:

\section{a) $1^{\text {st }}$ generation}

The elucidated data in Table (3) elucidate the delayed effect on both the experimented rates of Camphor fine dust $(5.0 \& 2.0)$ on the development of the raised alive larvae of the $1^{\text {st }}$ generation. 

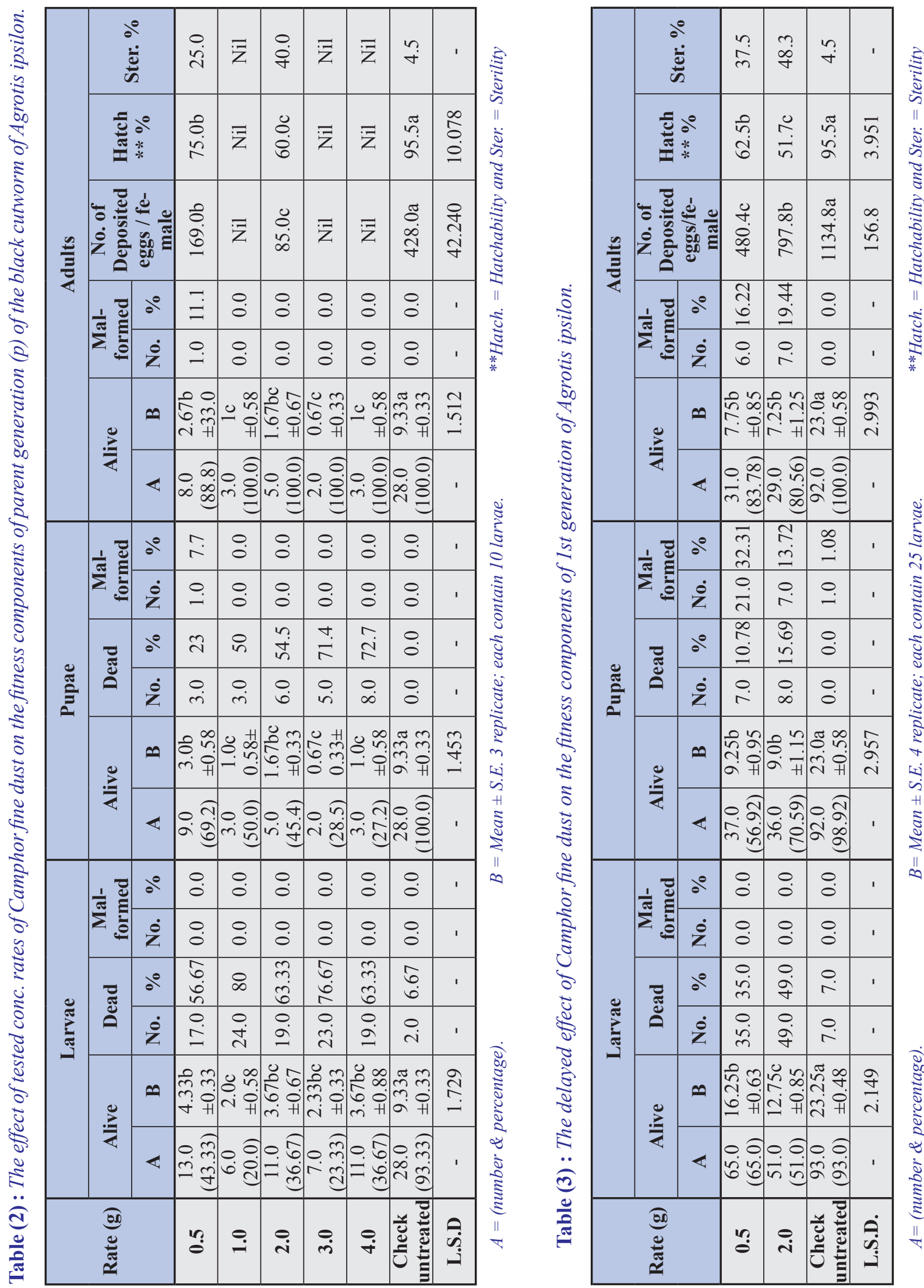
The numbers of alive and dead larvae, pupae, adults, deposited eggs per female and sterility percent of the pared couples of the emerged adult-moths of the $1^{\text {st }}$ generation were counted, calculated and recorded. The results clearly indicated the significant difference between both the tested rates and their effect on the raised larvae, compared to the check untreated ones. The highest comparative average number of the alive larvae $(23.25 \pm 0.48)$ was observed in the check treatment; followed by the tested conc. rate of $0.5 \mathrm{~g}(16.25 \pm 0.63)$. The lowest one of $12.75 \pm 0.85$ larvae was recorded for the tested rate of $2.0 \mathrm{~g}$. The highest larval mortality was observed in case of treatments with 2.0 and $0.5 \mathrm{~g}$ fine dusts (49.0 and $35 \%$ ) as a result of the occurring delayed effect post treatment of the parents. The mortality was somewhat decreased till $7.0 \%$ in the untreated check larvae.

Also, in comparison to the highest average number of the resulted pupae in control treatment $(23.0 \pm$ $0.58)$, the calculated averages numbers of the raised pupae were $(9.25 \pm 0.95$ and $9.0 \pm 1.15)$ in both the performed treatments of 0.5 and $2.0 \mathrm{~g}$, respectively. The highest percentage of dead pupae (15.65\%) was recorded at the tested rate of $2.0 \mathrm{~g}$, followed by $(10.78 \%)$ at $0.5 \mathrm{~g}$, compared to the complete absence of dead pupae in the untreated control. The lowest rate of the malformed pupae was recorded for the treatment of Camphor fine dust at the rate of $2.0 \mathrm{~g}$ $(13.72 \%)$, while the highest calculated rate of 32.31 $\%$ was revealed in the treatment of $0.5 \mathrm{~g}$ fine dust, compared to only one malformed pupa in the untreated check.

It was also found that the highest average number of emerged adult-moths $(23.0 \pm 0.58)$ was revealed in the untreated check, versus the lowest emergence rates of $(7.75 \pm 0.85)$ and $(7.25 \pm 1.25)$ at 0.5 and 2.0 $\mathrm{g}$, respectively. The delayed adverse bioperformancy of both the tested rates of 2.0 and $0.5 \mathrm{~g}$ increased the percentages of malformed adults up to $19.44 \& 16.22$ $\%$. Also, the highest gained number of the deposited eggs (1134.8/female) in control treatment was comparatively more reduced up to $480.4-797.8$ eggs/ female. That increase of deposited eggs in the raised (f1), versus comparatively the decrease of eggs/female numbers in (p) generation may be due to the difference of diet component in the prepared baits for feeding the treated $4^{\text {th }}$ instar larvae until the end of the $6^{\text {th }}$ ones of parent $(\mathrm{g}$ ) compared to the other fed larvae of (f1) generation which were reared on castor leaves along the lasted period developing larval instars (neonates) to pupae.

The highest hatchability of $95.5 \%$ recorded in the check untreated treatment and to more or less extent was reduced up to 51.7 and $62.5 \%$ at the tested conc. rates of 2.0 and $0.5 \mathrm{~g}$, respectively.

\section{b) $\underline{2}^{\text {nd }} \underline{\text { Generation }}$}

From the data in Table (4), it is clear that there is a distinct failure in the development of (f2) the survived larvae at both rates of 0.5 and $2.0 \mathrm{~g}$ Camphor fine dust. Also, it is obvious from the table that the highest average number of alive larvae recorded in the control treatment $(24.0 \pm 041)$; was more or less, lowered at the used Camphor fine dust at the rate of 2.0 and $0.5 \mathrm{~g}(16.25 \pm 0.85$ and $21.0 \pm 0.91$ larvae $)$. The highest larval mortality of $33.0 \%$ was also recorded at the conc. rate of $2.0 \mathrm{~g}$ fine dust: versus the revealed lowest larval mortality of $4.0 \%$ in check treatment.

Also, the highest average number of the resulted pupae $(24.0 \pm 0.41)$ was revealed in the untreated control, versus the lowest ones of $18.75 \pm 0.75 \&$ $13.75 \pm 1.7$ pupae which has been recorded for both evaluated conc. rates of 0.5 and $2.0 \mathrm{~g}$, respectively. The highest percentage of dead and malformed pupae $(5.97 \& 11.94 \%)$ was observed at $2.0 \mathrm{~g}$ conc. rate, followed by that of $0.5 \mathrm{~g}$ Camphor fine dust which recorded ( $4.67 \& 5.95 \%$ ), versus the absence of the last dead or malformed pupae in the untreated control. 
The rates of the emerged adults of the $2^{\text {nd }}$ generation (f2) were more than those of (f1) that averaged $18.0 \pm 0.58$ and $12.5 \pm 1.32$ adults, compared to 7.75 \pm 0.85 and $7.25 \pm 1.25$ adults in (f1) generation. It can be also seen that the tested rates of Camphor fine dust showed higher significant efficiency on the number of the deposited eggs per female. Compared to the high number of deposited eggs (711.6 eggs/ female) in control treatments, a low number of deposited eggs (345.6/female)was recorded for former treatment at $0.5 \mathrm{~g}$ Camphor fine dust; the lowest one (335.4/female) was observed for the tested rate of $2.0 \mathrm{~g}$ fine dust. Also, a high hatchability was noticed in control treatment which recorded $91.4 \%$, that versus the lowest one (35.0\%) which was observed for the tested rate of $2.0 \mathrm{~g}$ Camphor fine dust.

It can be also noticed that from tables $(2 \& 3)$ the reduction of the counted numbers of laid eggs /female in the control of (f2) generation (711.6) compared to (1134.8 eggs/female) in (f1) adults, also the decreased hatchability in the control of (f2) generation (91.4\%) Table (4) compared to (95.5\%) of (f1) Table (2) may be due to the high temperature which was observed during rearing of (f2) progeny rather than (fl) progeny.

\section{c) $3^{\text {rd }}$ generation}

The delayed effect of unprofitable biological performance of the tested rates of Camphor fine dust $(0.5 \& 2.0 \mathrm{~g})$ on the resulted immatures of the $3^{\text {rd }}$ generation, from the survived adult-moths of the $2^{\text {nd }}$ one post parent treatment ; that was apparent and exhibited in table (5). On the contrast of the survived larvae of the last generation post treatment of both tested rates, it was clear that this is the first time in which the number of the alive larvae at the rate of $2.0 \mathrm{~g}$ fine dust was more than the alive ones at the rate of $0.5 \mathrm{~g} \mathrm{(74.0} \mathrm{and} \mathrm{59.0),} \mathrm{respectively.}$

Moreover, the prominent observed reduction and / or increased in the recorded rates of the alive, dead , malformed pupae and the incipient adult-moths; in addition to the greatly decreased number of the deposited eggs per female and complete inhibition of egg hatching that represented an incidence of a numeral biophysiological disturbance ; that led to a state of a complete sterility at both of these tested rates of the evaluated Camphor fine dust. Furtherly, in other words the drastic unprofitable effects of the tested rates of Camphor fine dust on the studied biological characters of f1 \& f 2 insect-individuals had been followed by the distinct failure of $\mathrm{f} 3$ development due to the former treatment of (p) generation. That failure could be attributed to the cumulative effect of induced recessive lethal genes in both of the influenced sexes along the following developing $\mathrm{fl}$ $\&$ f2 generations post (p) one treatment, causing apparent unprofitable effects due to the occurrence of disturbed biological performance, which finally appeared at the beginning of the $3^{\text {rd }}$ generation.

\section{The effect of Jimson weed fine dust on the fitness components of A. ipsilon parent (p) generation.}

The presented data in Table (6) show that all of the tested rates of Jimson weed fine dust caused significant reduction of the mean number of surviving alive larvae of $A$. ipsilon, whereas larval treatment at the rate of $3.0 \& 4.0 \mathrm{~g}$ fine dust gave similar lowest mean numbers of alive larvae $(0.33 \pm 0.33)$, that followed ascendingly by the mean number of (1.67 \pm 0.33 larvae) at the rate of $2.0 \mathrm{~g}$ fine dust and at the rates of $1.0 \& 0.5 \mathrm{~g}$ Jimson weed fine dust. The nearly similar mean numbers of alive larvae (3.33 \pm 0.67 and $3.0 \pm 0.0$ ), versus the untreated check which showed the highest mean number of alive larvae $(9.33 \pm 0.33)$. The higher percentage of larval mortality $(60 \%)$ was recorded for the treatment of $0.5 \mathrm{~g}$ fine dust, which versus the lower value of 6.67 $\%$ in case of the untreated control. Higher percentage of malformed larvae ( $46.67 \& 40.0 \%$ ) was observed for both rates of $4.0 \& 3.0 \mathrm{~g}$, respectively, which versus a complete absence of malformed larvae in the control treatment. 


\begin{tabular}{|c|c|c|c|c|c|c|}
\hline \multirow{7}{*}{$\frac{\mathscr{n}}{E}$} & \multicolumn{2}{|c|}{$\begin{array}{l}\stackrel{0}{0} \\
\ddot{\Phi} \\
\dot{\omega}\end{array}$} & in & in. & $\underset{\infty}{\infty}$ & ' \\
\hline & \multicolumn{2}{|c|}{ 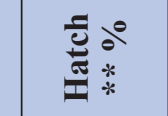 } & $\begin{array}{l}\stackrel{0}{0} \\
\stackrel{+}{f}\end{array}$ & $\begin{array}{l}0 \\
\ddot{0} \\
\ddot{n}\end{array}$ & $\frac{\stackrel{\pi}{+}}{\sigma}$ & $\begin{array}{l}\tilde{\sigma} \\
0 \\
0\end{array}$ \\
\hline & \multicolumn{2}{|c|}{ 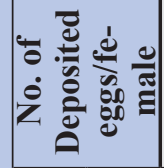 } & $\begin{array}{l}\text { b } \\
\dot{0} \\
m\end{array}$ & $\begin{array}{l}\text { fे } \\
\ddot{n} \\
\text { nे }\end{array}$ & $\frac{\overparen{\pi}}{\stackrel{\nabla}{\nabla}}$ & $\begin{array}{l}\alpha \\
\infty \\
=\end{array}$ \\
\hline & \multirow{2}{*}{$\sum^{\frac{\pi}{\pi}}$} & $\partial^{0}$ & $\stackrel{\circ}{\forall}$ & $\stackrel{\circ}{\circ}$ & $\begin{array}{l}\infty \\
0 \\
i\end{array}$ & ' \\
\hline & & $\dot{z}$ & $\stackrel{0}{\oplus}$ & $\stackrel{0}{i}$ & $\stackrel{\circ}{i}$ & ' \\
\hline & \multirow{2}{*}{ 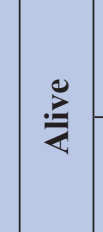 } & 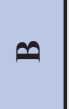 & $\begin{array}{l}0 \\
0 \\
0 \\
\infty \\
\infty\end{array}$ & 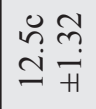 & 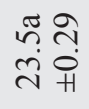 & $\stackrel{\stackrel{a}{i}}{i}$ \\
\hline & & $\ll$ & $\begin{array}{l}0 \\
\stackrel{0}{0} \\
0\end{array}$ & ○. & 워 & ' \\
\hline \multirow{6}{*}{ ڤ્ટ } & \multirow{2}{*}{ 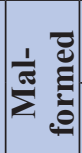 } & $\partial^{\theta}$ & $\begin{array}{l}\approx \\
\hat{n}\end{array}$ & $\stackrel{\Xi}{\Xi}$ & $\stackrel{\circ}{0}$ & ' \\
\hline & & $\dot{z}$ & in & $\stackrel{\circ}{\infty}$ & $\stackrel{\circ}{0}$ & 1 \\
\hline & \multirow{2}{*}{ تีّ } & $\partial^{\circ}$ & $\begin{array}{l}\stackrel{\circ}{+} \\
\dot{r}\end{array}$ & $\hat{a}$ & $\stackrel{\circ}{0}$ & ' \\
\hline & & $\dot{z}$ & $\stackrel{\circ}{\forall}$ & $\stackrel{\circ}{+}$ & $\stackrel{\circ}{0}$ & ' \\
\hline & \multirow{2}{*}{ 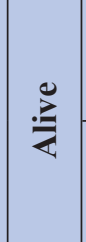 } & 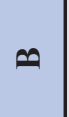 & $\begin{array}{l}\hat{n} \\
\stackrel{n}{0} \\
\infty \\
\infty\end{array}$ & $\mid \begin{array}{l}\ddot{n} \\
\stackrel{2}{m} \\
\dot{m}\end{array}$ & $\begin{array}{l}\stackrel{\Xi}{\sigma} \overrightarrow{+} \\
\dot{d}\end{array}$ & $\frac{n}{n}$ \\
\hline & & $\varangle$ & 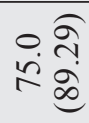 & $\begin{array}{l}0 \hat{\sigma} \\
i \dot{\delta} \\
i n \\
\dot{0}\end{array}$ & 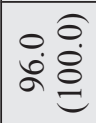 & ' \\
\hline \multirow{6}{*}{ 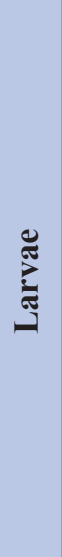 } & \multirow{2}{*}{$\sum^{\frac{D}{0}}$} & $\partial^{\circ}$ & $\because$ & $\stackrel{\circ}{\circ}$ & $\stackrel{0}{0}$ & 1 \\
\hline & & $\dot{\mathrm{z}}$ & $\because$ & $\stackrel{\circ}{\circ}$ & $\stackrel{\circ}{\circ}$ & ' \\
\hline & \multirow{2}{*}{ ت્ّ } & $\partial^{\circ}$ & $\stackrel{0}{0}$ & $\stackrel{\circ}{m}$ & $\stackrel{\circ}{\circ}$ & ' \\
\hline & & $\dot{Z}$ & $\stackrel{0}{0}$ & $\stackrel{\circ}{\text { m. }}$ & $\stackrel{\circ}{\forall}$ & ' \\
\hline & \multirow{2}{*}{ 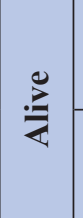 } & 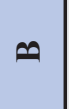 & 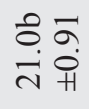 & 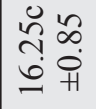 & 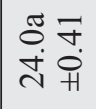 & $\underset{\text { ॄे }}{i}$ \\
\hline & & $\varangle$ & $\begin{array}{l}0 \\
\stackrel{0}{+} \\
\dot{\infty} \\
\dot{\infty}\end{array}$ & $\mid \begin{array}{cc}0 & 0 \\
i & 0\end{array}$ & 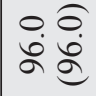 & $\begin{array}{l}\circ \\
\stackrel{0}{+} \\
\dot{\infty}\end{array}$ \\
\hline \multicolumn{3}{|c|}{ 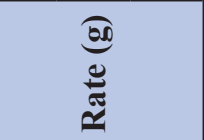 } & $\stackrel{n}{0}$ & $\stackrel{\stackrel{\leftrightarrow}{i}}{ }$ & 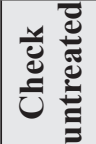 & $\stackrel{\stackrel{\leftrightarrow}{\dot{\leftrightarrow}}}{\dot{\leftrightarrow}}$ \\
\hline
\end{tabular}

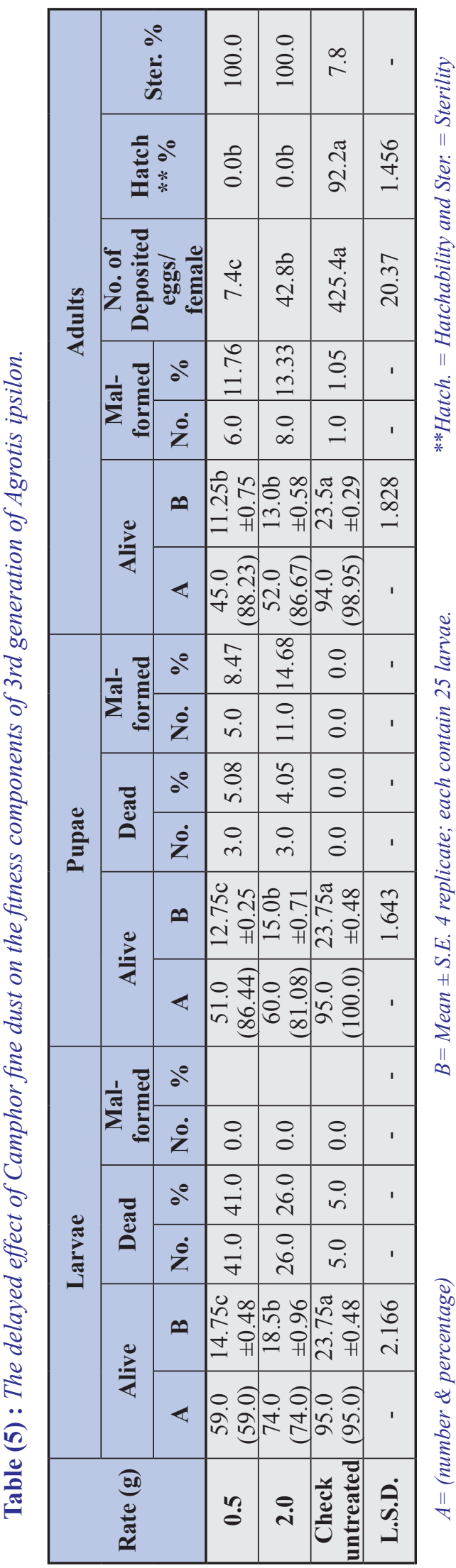




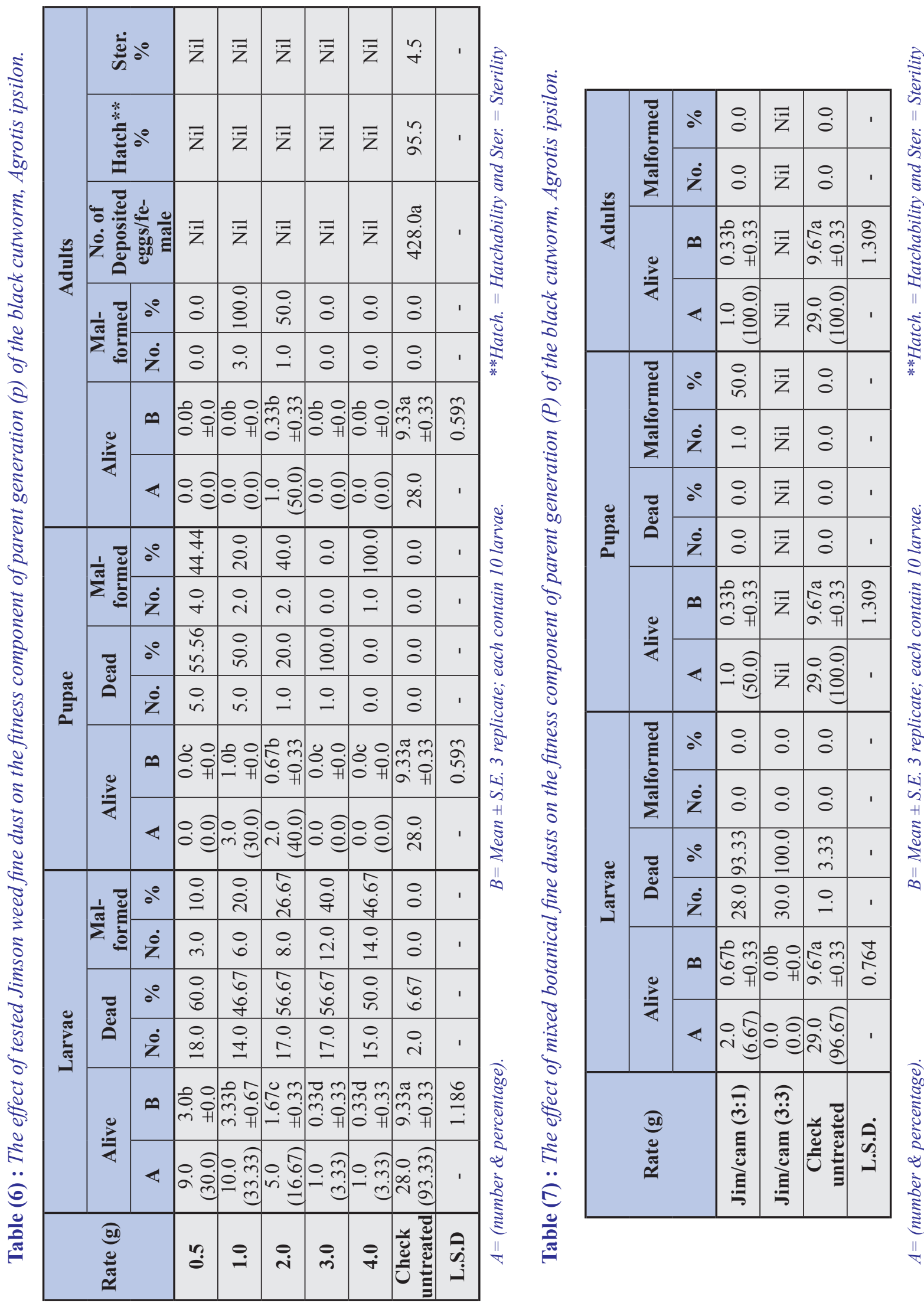


It was noticed that the highest average number of the resulted pupae ( $1.0 \pm 0.0$ pupae) was observed at the rate of $1.0 \mathrm{~g} \mathrm{w} / \mathrm{w}$ Jimson weed fine dust, while a complete absence of the resulted alive pupae was noticed for the tested rates of $0.5,3.0$ and $4.0 \mathrm{~g} \mathrm{w} / \mathrm{w}$ fine dust, which versus a high average number of $(9.33 \pm 0.33$ pupae) that was recorded for the control treatment. The highest calculated number of the dead pupae (5.0 pupae) was recorded in the treatments of Jimson weed at conc. rates of 0.5 and $1.0 \mathrm{~g}$ fine dust. The highest percentage of the dead pupae (100\%) and/or the absence of malformed pupae was observed for the conc. rate of $4.0 \mathrm{~g}(\mathrm{w} / \mathrm{w})$ fine dust.

Also, the only calculated mean number of emerged adults $(0.33 \pm 0.33$ adults $)$ was recorded at $2.0 \mathrm{~g}(\mathrm{w} / \mathrm{w})$ Jimson weed fine dust, that versus the complete absence of alive emerged adults at all the other tested conc. rates of Jimson weed fine dusts. (Table,6).

Noticeably, that detected a complete rapid failure of development in each of all these tested rates of Jimson weed fine dusts and that could be referred to the rapid occurrence of their adverse unprofitable biological performance against the developing stages of parent generation, due to the cumulative effect of the induced recessive lethal genes in both influenced stages of post larval treatment which led to a complete failure of development .

The presented data in Table (7) shows the revealed effectiveness of the evaluated fine dusts mixtures of each of Jimson weed with Camphor at rates of (3:1) and (3:3) gm. fine dust on the developmental sequence of the exposed larvae of parent generation on the prepared baits. The numbers and percentages of the resulted normal and / or malformed larvae, pupae and the incipient moths were calculated and recorded.

From Table (7) it is obvious that larval treatment with the baits of Jimson weed/ Camphor fine dust mixture at a rate of (3:1)gm gave a higher number of alive larvae (2larvae) compared to (29 larvae) in control treatment, while the bait of Jimson weed/ Camphor(3:3) gm fine dust recorded zero alive larvae.

In concern to the resulted numbers of the resulted alive pupae, were found in the mixture bait of Jimson weed/Camphor at a rate of (3:1) gm. the only detected number (1 pupa) of alive pupae in comparison to the untreated control, (29 pupae).

Also, the number of malformed pupae(1.0 pupa) was found for mixture bait of Jimson weed/Camphor at a rate of (3:1) gm fine dust compared to the complete absence of malformed pupae for the other bait.

\section{DISCUSSION}

Finally, from Tables (6\&7) as to the used botanical fine dusts the aforementioned results confirmed the highest efficient toxicity and unprofitable biological performance of the tested binary mixtures on the studied fitness components of the developing stages of the treated parent ( $p)$ generation. That rapid failure of (p) generation indicate a fastest toxic efficiency and occurrence of drastic biological effects during the period of $(p)$ generation development. That failure of development could be also attributed to the cumulative effect of induced recessive lethal genes in both affected pupal and imaginal stages during the period of $(p)$ generation post larval treatment.

In concern to our above exhibited results of the evaluated botanical fine dusts and their mixtures against the black cutworm, the literature of numerous conducted research works on the toxic effect and/or biological performance of experimented phytochemicals as essential or volatile oils and/or course and fine dusts against plenty species of insect-pests that were mentioned in the works of numerous researches, i.e., Zhou et al. (2000) against bollworm (Helicoverpa armigerd) and mosquito (Culex pipiens pallens); Jie et al. (2003) on the lepidopteran insectpest Pieris rapae and Plutella xylostella; AnQing and 
DeHua (2004) against cabbage worm (Pieris rapae); Chandel et al. (2006) on Helicoverpa armigera (Hubner); Ibrahim (2008) against potato tuber moth, Phthorimaea opercutella (Zeller); Ramanagouda and Srivastava (2008) on S. litura; (Basera and Srivastava, 2009) on Spodoptera litura Fabricius; HaiFeng et al. (2010) against cabbage worm (Pieris rapae); Rajguru et al. (2010 and 201 la, b, c) on Spodoptera litura Fab.; Rajguru and Sharma (2012) against Spodoptera litura; Osman et al. (2012) against the $4^{\text {th }}$ instars of Spodoptera littoralis. Bhatt and Srivastava (2014) investigated the insecticidal potential of Camphor $(C$. Camphora) oil against 8-day-old larvae of S. litura under laboratory conditions. Five concentrations of the Camphor oil $(0.5,1.0,1.5,2.0$ and 2.5 micro 1) were topically applied to the thoracic region of chilled (cold-immobilised) individual larva. Camphor oil at 1.5, 2.0 and 2.5 micro I/larva significantly decreased feeding in comparison to the control $\left(3.63 \mathrm{~cm}^{2}\right)$. The lowest feeding of $0.033 \mathrm{~cm}^{2}$ was observed at 2.5 micro 1 Camphor oil/larva. The mean weight gain was significantly decreased at 1.5, 2.0 and 2.5 micro I/larva (-0.07, -0.03 and $-0.04 \mathrm{~g}$, respectively) compared to the control $(0.240 \mathrm{~g})$. The highest mortality $(95.8 \%)$ at one day after exposure was recorded at 2.5 micro 1 Camphor oil/larva. The larvae failed to pupate at 2.5 and 2.0 micro 1 Camphor oil/larva and the significantly lowest pupation of $4.16 \%$ was recorded at 1.5 micro 1 Camphor oil/larva. No adult emergence was observed at 2.5, 2.0 and 1.5 micro 1 Camphor oil/larva, and only $69.4 \%$ adults could emerge at lower dose.

Moreover, Mesbah et al. (2006) studied the efficiency of some plant oils alone and/or combined with different insecticides on the cotton leaf worm $S$. littoralis (Boisd.). They showed that the development of the treated $4^{\text {th }}$ instar larvae was blocked due to the treatment with tested plant oils. With no exception, all the efficiently tested essential and/or volatile oils acted principally as insect growth inhibitors (IGIs) rather than anti-feedants causing disruption of the insect development, abnormal larvae, pupae and adults that finally were lead to death.
A similar trend of the performed trials on the efficiency of volatile oils and their mixtures on the soft scale insect Saissetia coffen infesting the sago palm, was elucidated by Mesbah et al. (2010). The toxic activity and delayed effects of tested botanical volatile oils (either bioassayed or admixed in the prepared baits) on the following generations (Fs) of the black cutworm A. ipsilon, after parents (P) treatment were studied by Mesbah et al. (2014 a\& b). It was revealed that all the tested oils were found to have more or less toxic activity and drastic effects on the inspected parameters of fitness components of the treated parent $(\mathrm{P})$ generation of the insect, in particular, pupae, emerged adult-moths and laid eggs/female. The assessed unprofitable delayed effects on the going on of the biological performance within the tested insects showed the adverse effects on the fitness components of the consequent generations $(\mathrm{Fs})$ post $(\mathrm{P})$ one treatment with each of the bioassayed oils or/and involved in the prepared baits ; which was finally followed by the distinct failure of insect development.

In addition, the biological performance and delayed effects of many botanical fine dusts and natural materials were investigated on the potato tuber moth, Phthorimea operculella (Zeller) (Mesbah et al., 20lla\&2012) and the rice weevil, Sitophilus oryzae (L.) (Mesbah et al., $201 \mathrm{I}$ b).

Pavela (2014) also tested the efficacy of 30 aromatic compounds and their mutual binary combinations for acute toxicity against the larvae Spodoptera littoralis. Based on a comparison of the lethal doses, the thymol, carvacrol and trans-anethole were selected as the most effective, and LDso was estimated for them at 9, 15 and 18 micro g/larva, respectively, and LD \% at 28, 35 and 41 micro g/larva, respectively. In total, 435 binary combinations were tested, of which 135 combinations showed a significant synergic effect, while 150 combinations showed a significant antagonistic effect on mortality. Only 6 substances were identified as being able to create a synergic effect with more than 20 substances: gamma-terpinene, 
limonene, p-cymene, trans-anethole, borneol and Camphor. L-carvone and gallic acid created an antagonistic effect with the highest frequency. The highest synergic effect was achieved for the combination of Camphor and borneol, with the place of expected mortality estimated at $4.8 \%$ and mortality at $88.6 \%$. In order to verify the synergic interaction of Camphor and borneol, the effectiveness in terms of acute toxicity for $S$. littoralis larvae was determined for three fundamental mixing ratios of the substances. Significantly different $\mathrm{LD}_{5} \mathrm{o}$ values (88 and 134 micro g/larva, respectively) were found for Camphor/borneol mixtures prepared in the ratios $2: 1$ and $1: 1$, respectively. The authors suggested that the information obtained can be used in the development of new botanical insecticides based on EOs, and particularly in the creation of formulations. On the other hand, Sharaby et al. (2020) found that the extracts of mint, zygophyllum, coriander, arnoglosse, harmel, and solanum indicated a total inhibition of egg deposition at $2.5 \%$ concentration; also, they provided high protections to the potato tubers from the potato tuber moth (PTM) infestation for about 3 months and without observations' effect on tubers germination.

\section{CONCLUSION}

Some botanical fine dust prepared from camphore and jasmon weed grass induced the latent delayed toxicity against Agrotis ipsilon. Great effects by the comphor were evaluated with all rate against the number of live larvae. whereas, highly efficient and the number of alive larvae ranged between 6 and 13 larvae out of 30 larvae compared to the untreated check (28 larvae). On the other hand, Jimson weed grass fine dust caused significant reduction of the mean numbers in the surviving alive larvae of $A$. ipsilon.

\section{REFERENCES}

- Abdel-Hadi, M.A. (1968): Biological and Ecological Studies on Agrotis ipsilon. Ph D. Thesis, Fac. Agric., Cairo Univ.
- Abdel-Mageed, A.A.F. (1997): Insecticidal Activity of Bacillus thurigensis and its mixtures with pesticides against Agrotis ipsilon. M.Sc. Alex. Univ., Egypt. 118.

- AnQing, Y. and DeHua, L. (2004): Studies on Biological Activity of Extract of dnnamomum Camphora (L.) Presl and Artemisia annua L. against cabbage worm. China Veg., (5): 14.

- Basera, A. and Srivastava, R.P. (2009): Effect of Plant Oils on feeding behaviour, growth and development of Spodoptera litura Fabricius. J. Insect Sci. (Ludhiana), 22(2):187.

- Beheedy, A.A. (1990): Toxicological and Histopathological studies on Agrotis ipsilon (Hufn.). Ph.D., Faculty Agric., Alex. Univ., Egypt.

- $\quad$ Bhatt, P. and Srivastava, R.P. (2014): Bioefficacy of Cinnamomum Camphora oil against Spodoptera litura in vitro. Annals Plant Prot. Sci., 22(2): 434.

- Chandel, S.F.; Singh, P.K. and Ahmad, R. (2006): Efficacy of NPV in association with botanicals for control of Helicoverpa armigera (Hubner) infesting chickpea. Annals Plant Prot. Sci., 14(1): 30.

- Claus, E.P.; Tyler, V.E. and Brandy, L.R. (1970): Pharmacognosy 6 Ed., Ind. Ed. Lea and febiger, Philadelphia, K. M. Varghese co., 518 pp.

- El-Kifl, A.H.; Nasr, E.A.; Ibrahim M.N. and Moawad, G.M. (1972): Effect of Host Plants on various stages of Agrotis ipsilon. Bull. Soc. Ent. Egypt, LVI: 103.

- Han, Zi.J. (1986): The virulence reaction and fastness variation of the black cutworm to several pesticides. J. Acta Phytophylacica Sin., 13(2): 125.

- HaiFeng, L.; Bing, Q. Wu and XiangGuo, L. (2010): Insecticidal Activities of alkaloids extracted from poisonous plants. J. Plant Dis. Pests, (6): 64.

- Ibrahim, M.Y. (2008): Study of effect of temperatures on the natural death and the biotic potential of potato tuber moth, Phthorimaea operculella (Zeller), (Lepidoptera: Gelechiidae) and used of some plant 
extracts as insect repellents against potato tuber moth under lab. conditions. Dirasat. Agric. Sci., 35(1/2): 1.

- Jie, L.; KeEr, Y.; GongFu, Y.; FangLin, T. and BaoFu, L. (2003): A study on stomach toxic effect of extracted solution of 20 tree species on vegetable insects. Acta Agriculturae Universitatis Jiangxiensis, 25(4): 581.

- Kandil, M.A.; Abdel-Aziz, N.F. and Sammour, E.A. (2003): Comparative toxicity of chlorfluazuron and leufenuron against cotton leaf worm Spodoptera littomlis (Boisd.). Egypt. J. Agric. Res., 2: 645.

- Li, F.; Chen, J.C. and Chen, J.H. (2002): Effects of Bt on respiration of the larvae of Agrotis ypsilon (Rottemberg). J. Nat. Enemies Insects, 24: 15.

- Li, Q.Y.F. and Zhang, G.A. (2008): Investigation of harming conditions of black cutworm, Agrotis ipsilon (Rottemberg) and the control of its insecticide in corn fields of North-West of Qian. J. Bull. Anhui. Agric. Sci., 14: 172.

- Mesbah, H.A. (1985): Evaluation of the potency of the biological compound Dipel against the spiny bollworm Earias jnsulana Boisd. J. Agric. Sci. Camb., 105: 587.

- Mesbah, H.A.; Mourad, A.K. and Ebieda, A.M. (1985): Toxicological studies of natural phytocompounds. 1: Synergism and Antagonism of pyrethroid orangophosphorous-Volatile oils of ornamental and medical plants against the house fly larvae, Musca domestica, L. Proc. $6^{\text {th }}$ Arab. Pesticide Conf. Tanta. Univ. (1): 423.

- Mesbah, H.A.; Tayeb, E.H.; Abdo, M.Z. and Elsayed, N. (1990): Toxicological studies of natural phytocompounds 3. efficiency of some volatile oils on the $4^{\text {th }}$ instar larvae of cotton leaf-worm, Spodoptera littoralis (Boisd.), J. pest control \& Environ. Sci., 2: 211 .

- Mesbah, H.A.; El-Kady, E.M. and El-Deeb, A.S. (1994a): Toxicological studies of natural phyto-compounds. IV. Effect of synthetic pyrethroids and volatile oils combinations against adults of the house fly,
Musca domestica complex. J. Uni. Ara. Biolo., 2(A): 45 .

- Mesbah, H.A.; EI-Deeb, A.S.; Bdr-Sohir, T. and El-Kady, E.M. (1994b): The toxic effect of certain phyto-compounds and biological preparations against the adult females of the house fly, Musca domestica L. Annals Agric. Sci. Moshtohor, 32(1): 537.

- Mesbah, H.A.; El-Kady, E.M. and El-Deeb, A.S. (1995): Toxicological studies of natural phytocompounds. Effect of organophosphorous compounds and volatile oils combinations against adults of the house fly, Musca domestica complex. J. Egypt. Ger. Soc. 16(E): 461.

- Mesbah, H.A.; Taman, F.A.; Fata, A.A.S. and Bakr, I.B. (2004): Evaluation of some new insecticides, insect growth inhibitors and plant oils against the cotton leaf-worm and sugar beet fly in sugar beet fields. Alex. Sci. Exch., 25(2): 341.

- Mesbah, H.A.; Mourad, A.K.; Rokaia, A.Z. (2006): Efficacy of some plant oils alone and/or combined with different insecticides on the cotton leaf-worm Spodoptera littoralis (Boisd.) (Eepidoptera: Noctuidae) in Egypt. Commun. Agric. Appl. Biol. Sci.,71(2): 305.

- Mesbah, H.A.; El-Sayed, N.A.; Mourad, A.K.; Abdel-Razak, S.I. and Abdel-Rahman, S. (2010): Efficacy of volatile oils and their mixtures against the soft scale insect, Saissetia coffeae (Walker) (Hemiptera: Coccidae) infesting the sago palm, cycas revolute in Alexandria Egypt. Comm. Appl. Biol. Sci. Ghent Univ., 75(3): 379.

- Mesbah, H.A.; El-Kady, M.B.; Gouda, R.M. and Ibrahim, G.M. (2011a): Efficiency of natural plants fine dusts on the fitness components of potato tuber moth Phthorimaea operculella (Zeller) (Lepidoptera: Gelechiidae) 1. Effect of Camphor and Citrus fine dusts. Minufiya J. Agric. Res., 36(1): 109.

- Mesbah, H.A.; Tayeb, E.H.M.; Elsayed, N.A.A.; El-Kady, M.B.A. and Greira, A.A.A. (2011b): Biological performance of certain botanical fine dusts, 
ash and sulphur powder against the rice weevil $\mathrm{Si}$ tophilus oryzae (E.) (Coleoptera; Curculionidae). Alex. Sci. Exch. J., 32(2): 171.

- Mesbah, H.A.; El-Kady, M.B.; Mourad, A.K.; Kordy, A.M.; Gouda, R.M. and Ibrakim, G.M. (2012): Efficiency of guva and lemon grass fine dusts on the potato tuber moth Phthorimaea operculella (Zeller) (Lepidoptera: Gelechiidae). Agric. Appl. Biol. Sci., 77(4): 699.

- Mesbah, H.A.; El-Sayed, N.A.; El-Kady, M.B.; Tayeb, E.H.; Mourad, A.K.; Kordy, A.M. and Henaidy, Z.M. (2014a): Efficacy of prepared baits alone or/and admixed four botanical oils on the viability of successive raised generations of Agrotis ipsilon (Hufnagel) (Insecta: Lepidoptera: Noctuidae) after treating the parent ones. Commun. Agric. Appl. Biol. Sci., 79(2): 185 .

- Mesbah, H.A.; Elsayed, N.A.; El-Kady, M.B.; Mourad, A.K.; Kordy, A.M. and Henaidy, Z.M. (2014b): Toxic activity and delayed effects of five botanical oils on the following generations of Agrotis ipsilon (Hugnagel) (Insecta: Lepidoptera: Noctuidae) after parents treatment. Agric. Appl. Biol. Sci.,79(2):129.

- Osman, H.H.; Fetch, B.E.A. and Mohammad, A.M. (2012): The potency of chloropyrifos and Camphor extract on Spodoptera littoralis (Boisd.). Egypt, Acad. J. Biol. Sci.: Entomology, 5(2):131.

- Pavela, R. (2014): Acute, synergistic and antagonistic effects of some aromatic compounds on the Spodoptera littoralis Boisd. (Lep., Noctuidae) larvae. Ind. Crops Prod., 60: 247.

- Rajguru, M.; Sharma, A.N. and Banerjee, S. (2010): Utilization indices of Spodoptera litura Fab. larvae as influenced by some plant extracts. Soybean Res., 8: 28.

- Rajguru, M.; Sharma, A.N. and Banerjee, S. (2011a): Evaluation of antifeedant properties of plant extracts against Spodoptera litura Fabricius larvae infesting soybean. J. Insect Sci. (Ludhiana), 24(4): 320.
- Rajguru, M.; Sharma, A.N. and Banerjee, S. (2011b): Toxicity symptoms of plant extracts on Spodaptera litura Fab. (Lepidoptera: Noctuidae) larvae. Soybean Res., 9: 116.

- Rajguru, M.; Sharma, A.N. and Banerjee, S. (2011c): Assessment of plant extracts fortified with Bacillus thuringiensis (Bacillales: Bacillaceae) for management of Spodoptera litura (Lepidoptera: Noctuidae). Int. J. Trop. Insect Sci., 31(1/2): 92.

- Rajguru, M. and Sharma, A.N. (2012): Comparative efficacy of plant extracts alone and in combination with Bacillus thuringiensis sub sp. kurstaki against Spodoptera litura Fab. larvae. J. Biopesticides, 5(1): 81 .

- $\quad$ Ramanagouda, S.H. and Srivastava, R.P. (2008): Effect of medicinal plant extracts on biological parameters of tobacco caterpillar, Spodoptera litura. Indian J. Plant Protec., 36(2): 196.

- $\quad$ Rice, J. and Coats, J.R. (1994): Insecticidal properties of several monoterpenoids to the house fly (Diptera: Muscidae), red flour beetle (Coleoptera: Temebrionidae) and southern corn root worm (Coleoptera: Chrsomelidae). J. Econ. EntomoL, 87: 1172.

- Salama, H.S.; Dimetry, N.Z. and Salem, S.A. (1970): The host preference and biology of the cotton leaf worm Spodoptera littoralis. Z. Ang. Entomol., 67: 261.

- $\quad$ Sellmkit, G.H. (1986): Pestizide undumweltschutz. Vieweg \& Sohu, Braunschweig, 466 pp.

- $\quad$ Schmutterer, H. (1992): Higher plants as sources of novel pesticides. In: Otto D, Weber B (eds) Insecticides. Mechanisms of action and resistance. Intercept Ltd, Antover.

- Sharaby, A.M.F.; Gesraha, M.A. and Fallatah, S.A.B. (2020): Botanical extracts against the potato tuber moth, Phthorimaea operculella (Zeller 1873) (Lepidoptera: Gelechiidae), during storage conditions. Egy. J. Biol. Pest Cont., 30: 93. 
- Vanichpakorn, P.; Ding, W. and Cen, X.X. (2010): Insecticidal activity of five Chinese medicinal plants against Plutella xylostella L. larvae. J. Asia Pacific Entomol., 13: 169.

- Zhou, X.; XiangDong, L.; JianZhong, Y.; ZhenZ Hua, T. and WangYi, L. (2000): Toxicity of cinnamomin - a new type II ribosome-inactivating protein to bollworm and mosquito. Insect Biochem. Mol. Biol., 30(3): 259 . 